\title{
Visual Inspection and Toothbrush Care: A Mother-Baby Paired Cross-Sectional Study
}

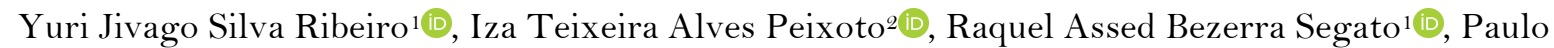 \\ Nelson-Filho ${ }^{1}$, Alexandra Mussolino de Queiroz ${ }^{1}$, Francisco Wanderley Garcia Paula-Silva ${ }^{1}(0)$
}

${ }^{1}$ Department of Pediatric Dentistry, School of Dentistry, University of São Paulo, Ribeirão Preto, SP, Brazil.

${ }^{2}$ School of Medicine and Public Health (Bahiana), Salvador, BA, Brazil.

Correspondence: Yuri Jivago Silva Ribeiro, Department of Pediatric Dentistry, School of Dentistry of Ribeirão Preto, University of São Paulo, Avenida do Café s/n, Monte Alegre, Ribeirão Preto, SP, Brazil. 14040-904. E-mail: yurijivago2@gmail.com

Academic Editor: Alessandro Leite Cavalcanti

Received: 25 May 2021 / Review: 09 August 2021 / Accepted: 15 August 2021

\begin{abstract}
How to cite: Ribeiro YJS, Peixoto ITA, Segato RAB, Nelson-Filho P, Queiroz AM, Paula-Silva FWG. Visual inspection and toothbrush care: a mother-baby paired cross-sectional study. Pesqui Bras Odontopediatria Clín Integr. 2022; 22:e2 10106. https://doi.org/10.1590/pboci.2022.002
\end{abstract}

\begin{abstract}
Objective: To evaluate the physical conditions and presence of residues of toothbrushes used by mothers and their babies and mothers' knowledge about toothbrush care. Material and Methods: This was a crosssectional study comprising a convenience sample represented by 60 mother-baby pairs. The mothers answered a questionnaire to evaluate their knowledge of toothbrush care. A calibrated dentist performed a visual inspection of the toothbrushes. Statistical analysis was performed using the chi-square and Fisher's exact tests, with a significance level of $5 \%$. Results: It was found that $82 \%$ of the mothers had never received instructions regarding the care of toothbrushes after use $(\mathrm{p}=0.024)$. Most of them believed that their toothbrushes $(70 \%)$ and their children's toothbrushes $(88 \%)$ were in good condition to use $(\mathrm{p}=0.043)$. However, most mother's toothbrushes presented an unacceptable deformity of the bristles $(65 \%)$ and the presence of residues $(60 \%)$. In addition, babies' toothbrushes also presented unacceptable deformities of the bristles (52\%) and residues (55\%). There was an association between the lack of instructions received by the mother and the presence of deformity and residues on the mother's toothbrush bristles $(\mathrm{p}=0.037$ and $\mathrm{p}=0.003$, respectively). Conclusion: Most mothers had never received instructions regarding toothbrush care, which is reflected in the condition of their and their baby's toothbrushes, which presented unacceptable physical conditions concerning deformation and presence of residues.
\end{abstract}

Keywords: Dental Devices, Home Care; Toothbrushing; Mothers; Child; Dentists. 


\section{Introduction}

Manual brushing is a fundamental personal care method for maintaining oral health. Although the ideal daily oral hygiene frequency has not yet been established, it is known that individuals who do not brush regularly and correctly have a higher incidence of oral diseases [1]. This is a public health problem [2]. One of the most common challenges in oral health prevention is controlling the dental biofilm [3]. Microorganisms present in dental biofilms are exposed to sugars from processed foods. The microorganisms metabolize these sugars as their energy source and release acids. The lack of consistent oral hygiene results in oral health problems $[4,5]$.

Chemical and mechanical agents effectively promote the removal of the dental biofilm. The chemical agents inhibit the accumulation and thickening of the biofilm through penetration, selectivity, and substantivity mechanisms, while the mechanical agents promote the physical removal of the biofilm through movement [6,7]. Toothbrushes are the most common mechanical agents used for this purpose. Before a new toothbrush is introduced to the market, regardless of whether it is rotatory or manual, the manufacturer must comply with several specifications. These include the stiffness of the bristles, head size, and materials used in manufacturing the toothbrush [6,8]. Toothbrushes should also be changed periodically every 3 or 4 months, or earlier if the bristles are worn [9]. A toothbrush loses its efficacy with use, interfering with the ability to remove the dental biofilm effectively $[6,10,11]$. However, despite these recommendations, many individuals replace their toothbrushes every $2-6$ months [6,9,12-15].

After-use care of the toothbrush is also important. The toothbrush should be stored appropriately after thorough cleansing to remove residual debris and microorganisms after use [16,17]. Knowledge regarding these aspects of toothbrush care appears to vary between different populations. The dentist's role in educating the patient may influence this care [6,12,18]. Parents are responsible for their children's oral care as young children depend on their guardians to maintain their oral health, mostly due to their lack of knowledge and immature motor skills development that affect the effectiveness of their oral hygiene practices [19,20]. Parents' oral hygiene habits have been shown to influence children's brushing behaviors [21,22], indicating that oral health education strategies should focus on children and the parents [23].

To date, no studies have investigated the knowledge of mothers regarding toothbrush care, storage after use, and conditions after use. Therefore, this study aimed to investigate mothers' knowledge regarding toothbrush care and macroscopically evaluate the toothbrushes used by mothers and their children. We hypothesized that mothers' knowledge on toothbrush care positively influences the care of their and their children's toothbrushes.

\section{Material and Methods}

Ethical Clearance

This study was approved by the Research Ethics Committee of the School of Dentistry of Ribeirão Preto, University of São Paulo, Brazil (CAAE: 2005.1.411.58.5). All the participants invited to participate in this study signed an informed consent form before enrolling.

\section{Study Design and Sample}

This was an observational cross-sectional study comprising a convenience sample and was conducted on a single day. Sixty pairs of mothers and children participated in this investigation, ranging from 21 to 35 years (mothers) and 6 to 36 months (children). The inclusion criteria were as follows: the child should have 
visited the Romeu System of the School of Dentistry of Ribeirão Preto at the University of São Paulo regularly, use a toothbrush, and be accompanied by his/her mother.

\section{Data Collection}

The mother answered a structured questionnaire with one calibrated examiner. The questionnaire included demographic data and information on the mothers' knowledge about toothbrush care, such as storage conditions, period of toothbrush exchange, and factors influencing the choice of a toothbrush.

The visual inspection of the brushes was performed by a single examiner who analyzed the toothbrushes. The calibration was done in a previous study by our group [24], who observed the characteristics of the toothbrushes: the size of the head, rigidity of the bristles, deformity of the bristles, and presence of residue. The degree of deformation of the bristles was scored using a modified criteria based on Raws et al. [25]. For example, scores of o (uncertainty regarding use) and 1 (some divergent bristles indicating low use) were grouped as "no deformation," and scores of 2 (majority of the bristles were divergent) and 3 (bristles were very divergent and improper for use) were grouped as the "presence of deformation." The toothbrush was also evaluated for the presence of residue (toothpaste, food, dust, mold, or other) via visual inspection, according to Massoni et al. [18]. The evaluator classified the toothbrush based on its condition. For example, no deformation and no residue versus deformation with or without residues. After data collection, oral health education on toothbrush care and brushing techniques were provided to the mothers.

\section{Data Analysis}

The data were tabulated using the Microsoft Office Excel 2016 program, and data analysis was performed using the company's Epi Info 7 program (Center for Disease Control and Prevention, Atlanta, Georgia, USA). Descriptive and statistical analyses were performed using the chi-square test, Fisher's test, and t-test. The significance level was set at $5 \%$.

\section{Results}

One hundred and twenty participants were enrolled in the study, representing 60 pairs of mothers and children. The mean age of the children was 22.4 months ( \pm 9.07 months), and that of the mothers was 26.5 years $( \pm 4.78$ years). Twenty-eight children $(46 \%)$ were male, and $32(54 \%)$ were female.

It was found that $82 \%$ of the mothers had never received instructions on after-use care of their toothbrushes $(\mathrm{p}=0.024)$. However, most of them believed that their toothbrushes $(70 \%)$ and those of their children $(88 \%)$ were in good condition $(\mathrm{p}=0.043)$.

The mothers reported that they replaced their toothbrushes every 3 to 4 months $(\mathrm{p}=0.482)$. Regarding the brush storage location at home, the bathroom cabinet was the place of choice $(>50 \%)$, followed by the brush holder or the sink $(\mathrm{p}=0.658)$. Most mothers used a toothbrush holder during transportation. When asked about their choice of toothbrushes, mothers reported that appearance and brand were the factors that most influenced their selection of toothbrushes (Table 1).

Table 1. Information regarding conditions and care of toothbrushes used by mother-baby pairs.

\begin{tabular}{lccccc}
\multicolumn{1}{c}{ Questions } & Mother & Baby & p-value \\
& $\mathrm{N}$ & $\%$ & $\mathrm{~N}$ & $\%$ & \\
\hline $\begin{array}{l}\text { How often do you change yours and your child toothbrush? } \\
\text { 1-2 Months }\end{array}$ & 11 & 18.0 & 16 & 26.0 & 0.482
\end{tabular}




\begin{tabular}{|c|c|c|c|c|c|}
\hline 3-4 Months & 34 & 56.0 & 28 & 46.0 & \\
\hline+5 Months & 15 & 26.0 & 15 & 26.0 & \\
\hline Do Not Know & 9 & 0.0 & 1 & 2.0 & \\
\hline Total & 60 & 100.0 & 60 & 100.0 & \\
\hline \multicolumn{6}{|c|}{ here do you keep yours and your child toothbrush at home? } \\
\hline Cabinet & 32 & 54.0 & 31 & 52.0 & 0.658 \\
\hline Sink & 10 & 16.0 & 13 & 21.0 & \\
\hline Brush Holder & 13 & 22.0 & 14 & 24.0 & \\
\hline Other & 5 & 8.0 & 2 & 3.0 & \\
\hline Total & 60 & 100.0 & 60 & 100.0 & \\
\hline \multicolumn{6}{|c|}{ here do you keep yours and your child toothbrush to bring to the clinic? } \\
\hline Bag & 28 & 46.0 & 26 & 43.0 & 0.926 \\
\hline Brush Holder & 31 & 52.0 & 33 & 53.0 & \\
\hline Other & 1 & 1.0 & 1 & 1.0 & \\
\hline Total & 60 & 100.0 & 60 & 100.0 & \\
\hline \multicolumn{6}{|c|}{ ow do you choose yours and your child toothbrush? } \\
\hline Appearance & 16 & 26.0 & 25 & 42.0 & 0.986 \\
\hline Dentist recommendation & 10 & 18.0 & 12 & 20.0 & \\
\hline Brand Name & 24 & 40.0 & 13 & 22.0 & \\
\hline Cost & 5 & 8.0 & 5 & 8.0 & \\
\hline Other & 5 & 8.0 & 5 & 8.0 & \\
\hline Total & 60 & 100.0 & 60 & 100.0 & \\
\hline
\end{tabular}

Most mothers used toothbrushes with medium head size and stiff bristles $(\mathrm{p}<0.05)$. Unacceptable deformities of the bristles were found in 39 toothbrushes $(65 \%)$, and the presence of residue was found in 36 toothbrushes (60\%) (Figures $1 \mathrm{~A}$ and $1 \mathrm{~B}$ ). Most of the children's toothbrushes had a small head size and soft bristles $(\mathrm{p}<0.05)$. Unacceptable deformities of the bristles were found in $52 \%$ of the toothbrushes, and the presence of residue was found in 33 toothbrushes (55\%) (Table 2 and Figures $1 \mathrm{C}$ and 1D).
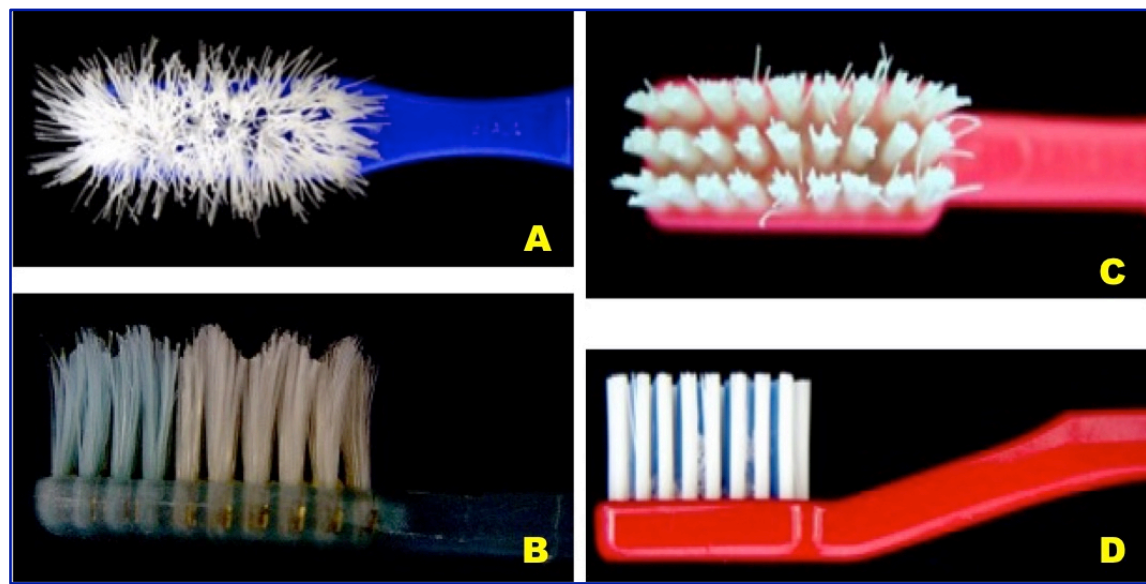

Figure 1. Toothbrushes used by mothers (A and B) and children (C and D): (A) Severe deformation of the bristles; (B) Presence of residues; (C) Slight deformation of the bristles and (D) Presence of residues after toothbrushing.

Table 2. Results of the inspection of toothbrushes used by mother-baby pairs.

\begin{tabular}{lccccc} 
& Questions & Mother & & Baby & \multicolumn{2}{c}{ p-value } \\
& $\mathrm{N}$ & $\%$ & $\mathrm{~N}$ & $\%$ & \\
\hline Size of toothbrush head & & & & & 0.0001 \\
$\quad$ Small & 6 & 10.0 & 44 & 74.0 & \\
Medium & 40 & 66.0 & 11 & 18.0 & \\
Large & 14 & 24.0 & 5 & 8.0 & \\
Total & 60 & 100.0 & 60 & 100.0 &
\end{tabular}

Stiffness of the bristles 


\begin{tabular}{|c|c|c|c|c|c|}
\hline Soft & 30 & 50.0 & 43 & 71.0 & 0.014 \\
\hline Medium & 27 & 45.0 & 17 & 29.0 & \\
\hline Hard & 3 & 5.0 & $\mathrm{O}$ & 0.0 & \\
\hline Total & 60 & 100.0 & 60 & 100.0 & \\
\hline \multicolumn{6}{|c|}{ Deformity of the bristles } \\
\hline Yes & 39 & 65.0 & 29 & 48.0 & 0.097 \\
\hline No & 21 & 35.0 & 31 & 52.0 & \\
\hline Total & 60 & 100.0 & 60 & 100.0 & \\
\hline \multicolumn{6}{|c|}{ Presence of residues in toothbrushes } \\
\hline Yes & 24 & 40.0 & 33 & 55.0 & 0.143 \\
\hline No & 36 & 60.0 & 27 & 45.0 & \\
\hline Total & 60 & 100.0 & 60 & 100.0 & \\
\hline \multicolumn{6}{|c|}{ Suitable conditions of toothbrushes for use } \\
\hline Yes & 23 & 38.0 & 24 & 40.0 & 0.99 \\
\hline No & 37 & 62.0 & 36 & 60.0 & \\
\hline Total & 60 & 100.0 & 60 & 100.0 & \\
\hline
\end{tabular}

There was an association between the lack of instructions received by mothers and the deformity in their toothbrush bristles $(\mathrm{p}=0.037)$, as well as an association between the lack of instructions and the presence of residue in the children's toothbrushes $(\mathrm{p}=0.003)$.

\section{Discussion}

The study hypothesis was confirmed because a lack of knowledge on toothbrush care negatively influenced the overall oral hygiene care. This study found a significant association between the lack of knowledge on toothbrush care and toothbrush deformity after use. The lack of knowledge of mothers and children regarding an adequate oral hygiene has been identified as an indicator of oral health problems [26]. Knowledge of proper oral hygiene is an important factor indicating good oral health [26].

There is a correlation between a longer use time and greater wear of toothbrushes [6,9]. In addition, the continuous use of the same toothbrush for six months decreases its effectiveness in removing dental biofilms and increases gingival inflammation [27]. The majority of individuals reported replacing their toothbrushes every 3-4 months. According to the American Dental Association [9], the presence of bristle deformities indicates that toothbrushes are not fit for use. Since the level of toothbrush wear is not influenced by the toothbrush design [11,27], we speculated that the deformity of the bristles could be related to the force applied during brushing. For this reason, the mothers received instructions on oral health care, toothbrush care, and brushing techniques.

In this study, a dentist visually examined the condition of the bristles and the presence of residue, indicating that they were not suitable for use. Meanwhile, the mothers believed that they were in proper conditions, which focused on the importance of oral health education and patient-professional communication. The deformity of toothbrush bristles is directly related to their decreased efficacy in dental biofilm removal [15]. In addition, the presence of residues after use may reflect a lack of oral health care information, as previously demonstrated in the literature [20].

Several factors such as cleaning and storage after every use influence the presence of residues on toothbrushes [28]. In this study, most participants stored their toothbrushes in the bathroom cabinet in their homes and in a toothbrush holder when visiting the dental office to avoid external contamination. Recommendations of storage include the use of a toothbrush holder and ventilated environments [29,30]. The American Dental Association [31] and the Society of Cardiology of the State of São Paulo [32] recommend that toothbrushes should be stored in a container with the bristles facing upward, without a holder. The 
toothbrushes of each family member should be stored separately and away from the toilet. Toothbrushes should also be disinfected after use to inhibit bacterial growth [16,31].

When queried about usage conditions, the mothers reported that the appearance and brand of the toothbrush were factors that most influenced toothbrush purchase. However, a visual examination by the dentist indicated that the toothbrushes were no longer suitable for use. These findings indicated a lack of information and highlighted the need for educational interventions for mothers. Despite these observations, the data presented in this study demonstrated the need for information on toothbrush care, not only about the condition of the bristles but also the presence of residue, thus preventing the proliferation of microorganisms and cross-contamination [18].

Despite the limitations of the study design with regard to convenience sampling based on a previous study carried out by our group [24], the data collection carried out in a single institution and the lack of socioeconomic data, our results showed relevant points and associations found between a lack of related knowledge and toothbrush care. Considering that the objective of this study was to investigate the knowledge of mothers who visited the Clínica de Odontopediatria with their children, on the proper care of a toothbrush and to evaluate the macroscopic form of the state of their and their children's toothbrushes, we will not discuss, in this article, the limitations pointed out. It is, therefore, the incentive for further research so that new ideas and changes in the study design are debated to provide subsidies for changing the identified framework.

\section{Conclusion}

Most mothers do not receive adequate instructions regarding toothbrush care. The lack of knowledge was reflected in the state of their toothbrushes and the toothbrushes of their children. This knowledge gap was identified because most of the toothbrushes investigated were physically unacceptable, showing deformation and the presence of residue.

\section{Authors' Contributions}

\begin{tabular}{|c|c|c|}
\hline YJSR & (iD) https://orcid.org/0000-0001-5858-4318 & Methodology, Investigation, Resources, Data Curation and Writing - Original Draft. \\
\hline ITAP & (i) https://orcid.org/0000-0002-8072-5938 & Conceptualization, Data Curation and Writing - Review and Editing. \\
\hline RABS & (iD) https://orcid.org/0000-0002-1935-7451 & Methodology, Data Curation and Writing - Review and Editing. \\
\hline PNF & (D) https://orcid.org/0000-0001-8802-6480 & Methodology and Writing - Review and Editing. \\
\hline AMQ & (iD) https://orcid.org/0000-0003-2900-5000 & Conceptualization and Writing - Review and Editing. \\
\hline FWPS & (i) https://orcid.org/0000-0001-8559-532X & $\begin{array}{l}\text { Conceptualization, Methodology, Formal Analysis, Resources, Data Curation and Writing - } \\
\text { Review and Editing. }\end{array}$ \\
\hline
\end{tabular}

\section{Financial Support}

None.

\section{Conflict of Interest}

The authors declare no conflicts of interest.

\section{Data Availability}

The data used to support the findings of this study can be made available upon request to the corresponding author.

\section{References}

[1] Jepsen S, Blanco J, Buchalla W, Carvalho JC, Dietrich T, Dörfer C, et al. Prevention and control of dental caries and periodontal diseases at individual and population level: consensus report of group 3 of joint EFP/ORCA workshop on the boundaries between caries and periodontal diseases. J Clin Periodontol 2017; 44(Suppl 18):S85-S93. https://doi.org/10.1111/jcpe.12687 
[2] Frencken J. Caries epidemiology and its challenges. Monogr Oral Sci 2018; 27:11-23. https://doi.org/10.1159/000487827

[3] Sekino S, Ramberg P, Uzel NG, Socransky S, Lindhe J. Effect of various chlorhexidine regimens on salivary bacteria and de novo plaque formation. J Clin Periodontol 2003; 30(10):919-25.

https://doi.org/10.1034/j.1600-051x.2003.00420.x

[4] Patro-Gołąb B, Zalewski BM, Kołodziej M, Kouwenhoven S, Poston L, Godfrey KM, et al. Nutritional interventions or exposures in infants and children aged up to 3 years and their effects on subsequent risk of overweight, obesity and body fat: a systematic review of systematic reviews. Obes Rev 2016; 17(12):1245-57. https://doi.org/10.1111/obr.12745

[5] Ribeiro CCC, Silva MCBD, Nunes AMM, Thomaz EBAF, Carmo CDS, Ribeiro MRC, et al. Overweight, obese, underweight, and frequency of sugar consumption as risk indicators for early childhood caries in Brazilian preschool children. Int J Paediatr Dent 2017; 27(6):532-539. https://doi.org/10.1111/ipd.12292

[6] Van Leeuwen MPC, Van der Weijden FA, Slot DE, Rosema MAM. Toothbrush wear in relation to toothbrushing effectiveness. Int J Dent Hyg 2019; 17(1):77-84. https://doi.org/10.1111/idh.12370

[7] Van der Weijden FA, Slot DE. Efficacy of homecare regimens for mechanical plaque removal in managing gingivitis a meta review. J Clin Periodontol 2015; 42(Suppl):77S-91S. https://doi.org/10.1111/jcpe.12359

[8] Schmidt JC, Astasov-Frauenhoffer M, Waltimo T, Weiger R, Walter C. Influence of the oscillation frequency of different side-to-side toothbrushes on noncontact biofilm removal. Clin Oral Investig 2018; 22(6):2141-7. https://doi.org/10.1007/s00784-017-2305-x

[9] ADA Science Institute. Toothbrushes. Available from: https://www.ada.org/en/about-the-ada/ada-positionspolicies-and-statements/statement-on-toothbrush-care-cleaning-storage-and-. [Accessed on August 20, 2020].

[10] Kreifeldt JG, Hill PH, Calisti LJ. A systematic study of the plaque removal efficiency of worn toothbrushes. J Dent Res 1980; 59(12):2047-55. https://doi.org/10.1177/00220345800590120401

[11] Dean DH, Beeson LD, Cannon DF, Plunkett CB. Condition of tooth- brushes in use: correlation with behavioral and socio-economic factors. Clin Prev Den 1992; 14(1):14-8.

[12] Daly CG, Marshall RI, Lazarus R. Australian dentists' views on toothbrush wear and renewal. Aust Dent J 2000; 45:254-6. https://doi.org/10.1111/j.1834-7819.2000.tboo260.x

[13] Malekafzali B, Biria M, Tadayon N, Abbasi H. Comparison of plaque removal efficacy of new and 3-month-old toothbrushes in children. East Mediterr Health J 2011; 17(2):115-20. Erratum in: East Mediterr Health J 2011; $17(3): 249$.

[14] Adeniyi AA, Oyapero A, Ajieroh V, Sofola O, Asiyanbi O. Effect of health education intervention conducted by Primary Health Care workers on oral health knowledge and practices of nursing mothers in Lagos State. J Public Health Afr 2018; 9(2):833. https://doi.org/10.4081/jphia.2018.833

[15] Rosema NA, Hennequin-Hoenderdos NL, Versteeg PA, van Palenstein Helderman WH, van der Velden U, van der Weijden GA. Plaque-removing efficacy of new and used manual toothbrushes - a professional brushing study. Int J Dent Hyg 2013; 11(4):237-43. https://doi.org/10.1111/idh.12021

[16] Nelson-Filho P, Faria G, da Silva RA, Rossi MA, Ito IY. Evaluation of the contamination and disinfection methods of toothbrushes used by 24- to 48-month- old children. J Dent Child 2006; 73(3):152-8.

[17] Nelson-Filho P, Pereira MS, De Rossi A, da Silva RA, de Mesquita KS, de Queiroz AM, et al. Children's toothbrush contamination in day-care centers: how to solve this problem? Clin Oral Investig 2014; 18(8):1969-74. https://doi.org/10.1007/s00784-013-1169-y

[18] Massoni ACLT, Silva MCA, Perazzo MF, Pereira RVS, Pessoa CP, Granville-Garcia AF. Physical conditions and conditioning of toothbrushes for preschool children. Rev Odontol 2015; 51(2):96-103.

[19] Coutinho PG, Bittar P, Ditterich RG, Santos FA, Wambier DS. Evaluation of the wear index of toothbrushes used by preschool children. Rev Odontol UNESP 2007; 36(1):97-101.

[20] Passos IA, Massoni ACLT, Ferreira JMS, Forte FDS, Sampaio FC. Physical conditions and conditioning of toothbrushes for preschool children. Arq Odontol 2015; 51(2):96-103.

[21] Retnakumari N, Ciriac G. Childhood caries as influenced by maternal and child characteristics in pre-school children of Kerala-an epidemiological study. Contemp Clin Dent 2012; 3(1):2-8. https://doi.org/10.4103/0976-237X.94538

[22] Castilho ARF, Mialhe FL, Barbosa TS, Puppin-Rontani. Influence of family environment on children's oral health: a systematic review. J Pediat 2013; 89(2):116-23. https://doi.org/10.1016/j.jped.2013.03.014

[23] Okada M, Kawamura M, Kaihara Y, Matsuzaki Y, Kuwahara S, Ishidori H, et al. Influence of parents' oral health behaviour on oral health status of their school children: an exploratory study employing a causal modelling technique. Int J Paediatr Dent 2002; 12(2):101-8. https://doi.org/10.1046/j.1365-263x.2002.00338.x

[24] Almeida-Junior LA, Mellara TS, Inácio GC, Silva RAB, Nelson-Filho P, Queiroz AM, et al. Maintenance and physical conditions of toothbrushes used by children with or without special needs: a cross-sectional study. Rev Odontol Bras Central 2021; 30(89):128-40. https://doi.org/10.36065/robrac.v30i89.1418

[25] Rawls HR, Mkwayi-Tulloch NJ, Casella R, Cosgrove R. The measurement of toothbrush wear. J Dent Res 1989; 68(12):1781-5. https://doi.org/10.1177/00220345890680121201 
[26] Beljan M, Puharić Z, Žulec M, Borić D, Neumuller KR. Parent's and children's behavior and knowledge about oral health. Acta Med Croatica 2016; 70(3):165-71.

[27] Schmickler J, Wurbs S, Wurbs S, Kramer K, Rinke S, Hornecker E, et al. The influence of the utilization time of brush heads from diferente types of power toothbrushes on oral hygiene assessed over a 6-month observation period: A randomized clinical trial. Am J Dent 2016; 29(6):307-14.

[28] Peker I, Akarslan Z, Basman A, Haciosmanoglu N. Knowledge and behavior of dentists in a dental school regarding toothbrush disinfection. Braz Oral Res 2015; 29:48. https://doi.org/10.1590/1807-3107BOR-2015.vol29.0048

[29] Ankola AV, Hebbal M, Eshwar S. How clean is the toothbrush that cleans your tooth?. Int J Dent Hyg 2009; 7(4):237-40. https://doi.org/10.1111/j.1601-5037.2009.00384.x

[30] Moreira ACS, Cavalcante GM. Influence of hygienization on the contamination of toothbrushes: prevention and care. Arq Ciênc Saúde UNIPAR 2008; 12(1):99-103.

[31] ADA Division of Communications. For the dental patient. Toothbrush care, cleaning and replacement. J Am Dent Assoc 2006; 137(3):415. https://doi.org/10.14219/jada.archive.2006.0193

[32] Sociedade de Cardiologia do Estado de São Paulo. Redobre a atenção com a higiene bucal e com a escova de dentes, na pandemia. 2020. Available from: https://Socesp.org.br/noticias/sem-categoria/redobre-a atencao-com-a-higienebucal-e-com-a-escova-de-dentes-napandemia. [Acessed on September 2020]. [In Portuguese]. 